\title{
LOS DERECHOS SOCIALES EN EL CONSTITUCIONALISMO DE LA CRISIS: UNA PERSPECTIVA COMPARADA
}

\author{
GIUSEPPE FRANCO FERRARI \\ Catedrático de Derecho Constitucional \\ Universidad Bocconi. Milán
}

\section{SUMARIO}

I. Algunas consideraciones introductorias. II. Gran Bretaña. III. Estados Unidos. IV. Alemania. V. Italia. VI. Francia. VII. España. VIII. Portugal. IX. Algunas conclusiones.

\section{ALGUNAS CONSIDERACIONES INTRODUCTORIAS}

El equilibrio entre derechos sociales y recursos financieros, entre definición de la consistencia y protección de la ciudadanía social, por un lado, y límites de la Hacienda pública, por el otro, es un asunto básico en la vida y en el funcionamiento del Estado social de Derecho. Como tal, se ha manifestado en diferentes épocas y de manera problemática en todos los ordenamientos que se inspiran en este modelo y han adoptado sus principios. Las formas adoptadas han dependido de la estructura constitucional de los sistemas jurídicos, de la interpretación del principio de separación de los poderes, de la organización de sus fuentes, del tradicional rol del poder judicial, y de muchos otros factores que pueden manifestarse con diferente fuerza en varios tiempos y lugares. A duras penas es posible sintetizar la variedad de manifestaciones y de soluciones. Por lo tanto, solo se puede ofrecer una reseña de algunos de los principales ordenamientos occidentales y de su acercamiento a este nudo de la crisis económico-financiera que se ha manifestado en los últimos diez años en la totalidad de los Estados. Los principales estudios dedicados a ese tema ${ }^{1}$ arrancan de años en los que la crisis todavía no se había

1 Como M. LANGFORD (ed.), Social Rights Jurisprudence. Emerging Trends in International and Comparative Law, Cambridge, 2008; M. TushneT, Weak Courts, Strong Rights. Judicial Review and Social Welfare Rights in Comparative

UNED. Teoría y Realidad Constitucional, núm. 43, 2019, pp. 349-370 
manifestado en toda su gravedad. Esta breve reseña tiene pues la ambición de averiguar las condiciones de los derechos sociales en condiciones de extraordinaria austeridad.

\section{GRAN BRETAÑA}

El ordenamiento inglés ofrece el ejemplo más típico de la resistencia a dejar a los jueces la búsqueda del punto de equilibrio entre distribución de recursos escasos, reivindicación de derechos prestacionales y obligaciones positivas. La clásica doctrina británica de la supremacía del Parlamento supone un obstáculo a una intervención judicial demasiado activista o penetrante y, muy a menudo, impone a los juzgadores que dejen a las asambleas legislativas cualquier operación de redistribución de recursos, limitándose a un self-restraint, conducta justificada por el desarrollo de la «non-justiciability doctrine», con la posible excepción de los casos de manifiesta irracionalidad.

En primer lugar, la ausencia de una constitución formal impide al poder judicial revisar la racionalidad de los criterios de la elección legislativa en la distribución de los recursos entre los diferentes canales del gasto exigido por el welfare state. La soberanía parlamentaria no permite una invasión judicial de ámbitos reservados a las decisiones políticas.

En consecuencia, la política económica nacional no puede ser revisada desde el punto de vista de las cuentas de la administración ${ }^{2}$, salvo que se pueda poner de manifiesto una macroscópica irracionalidad ${ }^{3}$. La prohibición incluye decisiones administrativas tanto de autoridades locales como sanitarias o asistenciales ${ }^{4}$. Una excepción puede ser admisible cuando el tema de los recursos financieros no es relevante $^{5}$ por admisión, contenida en la motivación del acto, de la autoridad implicada.

Constitutional Law, Princeton, N.J., 2008. Más recientemente se ocupan de la crisis del constitucionalismo y de la crisis en general X. Contiades (ed.), Constitutions in the Global Financial Crisis. A Comparative Analysis, Farnham, 2013 y T. Beukers, B. De Witte, C. Kilpatrick, Constitutional Change through Euro-crisis Law, Cambridge, 2017.

2 Vid por ejemplo Nottinghamshire CC v Secretary of State for the Environment and another appeal, [1986] AC 240 y R v Secretary of State for the Environment, ex p Hammersmith and Fulham LBC, [1991] AC 521.

3 Se habla en ese caso de Wednesbury review o de rationality review, desde el precedente Associated Provincial Picture Houses v Wednesbury Corp., [1948] K.B. 223, por mano de Lord Greene M.R. Todos los manuales de derecho administrativo y público tratan difusamente de este principio: vid por ejemplo H.W.R. Wade, C.F. Forsyth, Administrative Law, Oxford, 9. ${ }^{a}$ ed., 2004, 233 ss.; C. Lewis, Judicial Remedies in Public Law, Londres, 3. a ed., 2004, cap. 1; T.A.O. EndicotT, Administrative Law, Oxford, 2009, cap. 7.; P. CANE, L. Mcdonald, Administrative Law. Legal Regulation of Governance, Oxford, 2009, 179 ss.

4 Como la decisión de negar terapias contra el cáncer a una niña de nueve años con la motivación de que los recursos limitados deben ser utilizados para el beneficio del máximo número de pacientes, «juicio que no compite a los juzgados»: R v Cambridge Health Authority, ex p B, [1995] All ER 129 (CA).

5 Como en R (on the Application of Anne Marie Rogers) v Swindon NHS Primary Care Trust, Secretary of State for Health, [2006] EWCA Civ 392. Aquí el Primary Care Trust quería negar el uso de un fármaco anti-cáncer experimental, todavía no autorizado por la European Medicine Agency. 
También puede admitirse el control judicial de una actividad administrativa cuya naturaleza parezca más rutinaria que política («distinction between policy and operational decisions» $)^{6}$. En otras palabras, la discrecionalidad administrativa, con tal que pueda deducirse en forma clara de la letra de la ley, se configura como un límite del control jurisdiccional ${ }^{7}$. Los criterios generales de interpretación de las leyes condicionan la medida de discrecionalidad administrativa y, como consecuencia, la amplitud de la revisión judicial de la acción administrativa ${ }^{8}$.

Muy diferente es la disciplina de los daños que el poder judicial puede reconocer al titular de derechos sociales. En este ámbito, sin embargo, los tribunales ${ }^{9}$ y la doctrina invitan a un acercamiento cuidadoso y moderado, fundándose sobre consideraciones bastante parecidas a las tradicionales ${ }^{10}$.

Otro espacio más abierto a la intromisión del poder judicial en la acción administrativa para garantizar el disfrute de derechos sociales es el de la protección de algunas expectativas legítimas, es decir, fundadas en anteriores actos administrativos. Es el caso de una persona mayor de edad acogida en asilo, considerada titular de una esperanza de vida, que no le puede ser retirada ${ }^{11}$. En otros casos análogos, sin embargo, la presencia de una expectativa legítima puede no ser bastante para ordenar una prestación social, cuando por ejemplo el impacto respecto de terceras partes no representadas en el juicio pueda ser excesivo ${ }^{12}$.

Además, cada vez que la literalidad de la ley que regula un servicio social está formulada en términos amplios y vagos o imprecisos, hay que entender que el mandato legislativo a la administración es discrecional y no hay espacio para extraer derechos individuales ${ }^{13}$. Esta doctrina toma nombre de «target or general duties doctrine» ${ }^{14}$.

\section{ESTADOS UNIDOS}

No existe en el sistema jurídico estadounidense un consenso general con respecto a la idea de unos verdaderos derechos sociales $y$, por lo tanto, falta en el

6 Como en Anns v Merton LBC, $[1978]$ AC 728

7 Vid por ejemplo, en doctrina, F.A.R. BEnNion, Judgement and Discretion Revisited: Pedantry or Substance? [2005] PL 707.

8 M. Hertough, S. Halliday (eds.), Judicial Review and Bureaucratic Impact, Cambridge, 2002.

9 V. por ejemplo Anufrijeva and Another v Southwark London Borough Council y casos conectados, [2003] EWCA Civ 1406, [2004] QB 1124.

10 Como C. Harlow, State Liability: Tort Law and Beyond, Oxford, 2004, 56 ss. y Lord Woolfe, The Human Rights Act 1998, in M. Andenas, D. Fairgrieve (eds.), Judicial Review in International Perspective, vol. II, Deventer, 2000, 433 ss.

11 Como en R v North and East Devon Health Authority, ex p Coughlan, [2001] Q.B. 213.

12 V. R v London Borough of Newham, ex p Bibi and Al-Nashed, [2002] 1 WLR237.

13 R v Inner London Education Authority, ex parte Ali, (1990) 2 Admin LLR 822 y R (A) v Lambeth LBC [2001] EWCA Civ 1624.

14 Esta teoría está bién descrita en J.A. KING, The Justiciability of Resource Allocation, 70 Mod. L. Rev. 197,214 ss. (2007).

UNED. Teoría y Realidad Constitucional, núm. 43, 2019, pp. 349-370 
panorama jurisprudencial y doctrinal un análisis del problema de la estabilidad presupuestaria frente a los derechos sociales.

Hubo un ciclo del derecho constitucional en el que los dos profesores punteros de la escuela de Harvard, Frank I. Michelman y Lawrence H. Tribe, emprendieron un esfuerzo de relectura sistemática de las normas constitucionales, proponiendo una interpretación forzada de varias líneas de casos de argumentación compleja y sentido dudoso para llegar a la conclusión de la conveniencia de usar una interpretación post-liberal del principio de igualdad y avanzar en una transición de la democracia americana al modelo del welfare State.

En 1969, Michelman ${ }^{15}$ formuló la teoría que la «revolución igualitaria» de la edad de Warren había introducido en una sociedad construida alrededor de los valores de la libertad del mercado y de individualismo competitivo, el reconocimiento de una expectativa de niveles mínimos de bienestar adecuados a «unas necesidades justas». La eliminación de la pobreza, fuente primaria de las desigualdades sociales, habría sido elevada a objetivo constitucional con obvias implicaciones para el régimen de los servicios sociales. Esta formulación, ya cumplida antes del advenimiento a la presidencia de la Corte Suprema de Warren E. Burger en 1969, había sido ya precisada — a la búsqueda de bases teóricas más estables- en el neo-contractualismo de Rawls, que mientras tanto había desarrollado de forma definitiva la teoría política de la justicia distributiva ${ }^{16}$. El «difference principle» de la concepción de Rawls, que sustenta un equilibrio de libertad e igualdad, típico del Estado social, ha sido utilizado como guía de unas acciones de reforma social que pasan por la consagración de los welfare rights ${ }^{17}$.

En su versión más desarrollada, la tesis de la incorporación de los derechos sociales en el contexto constitucional ${ }^{18}$ ha legitimado la garantía constitucional de los derechos a la educación, a la vivienda, al tratamiento sanitario y a la asistencia social. Todo ello de acuerdo no solamente con las partidas del presupuesto, en realidad siempre lábiles, sino sobre abundante jurisprudencia de la Corte Burger, que han encontrado en la famosa nota al pie cuarta del caso de Carolene Products ${ }^{19}$ su más completa enunciación; así como con el modelo de fortalecimiento de la representación construido por Ely ${ }^{20}$. Gracias a su conexión con el argumento histórico-sistemático, los derechos sociales pudieron ser concebidos como «back-

15 F.I. Michelman, The Supreme Court, 1968 Term-Forward: On Protecting the Poor through the Fourteenth Amendment, Harv. L. Rev. 7-59 (1969).

16 J. Rawls, A Theory of Justice, Cambridge, Mass., 1971.

17 F.I. Michelman, In pursuit of Constitutional Welfare Rights: One View of Rawls' Theory of Justice, 121 U. Pa. L. Rev. 962 ss. (1973).

18 V. por ejemplo F.I. Michelman, Welfare Rights in a Constitutional Democracy, 1979 Wash. U.L. Q. 659; Formal and Associational Aims in Procedural Due Process, J. Pennock (ed.), Due Process (Nomos XVIII), 126 ss (1977) y States' Rights and States' Roles: Permutations of "Sovereignty» in National League of Cities v. Usery, 86 Yale L. J. 1165 ss (1977).

19 U.S. v. Carolene Products Co., 304 U.S. 144 (1938)

20 J.H. Ely, Democracy and Distrust: A Theory of Judicial Review, Cambridge, Mass., 1980. 
ground rights», según la terminología de Dworkin ${ }^{21}$, una condición previa de la democracia representativa, y venir incluidos en el núcleo de los derechos plenamente justiciables y exigibles por la Corte Suprema durante la presidencia de Burger, ampliando la lista de las posiciones jurídicas subjetivas constitucionalmente protegidas.

Esta teoría de la formalización de los derechos sociales ha encontrado adhesiones $^{22}$ pero también fuertes disensos. Los críticos han puesto el acento sobre el problema de la reconducción de los derechos sociales a las normas constitucionales formales ${ }^{23}$, negando la comprensión de las cláusulas de la XIV Enmienda como una cláusula abierta, susceptible de incluir expectativas diferentes a las enumeradas en el texto originario, incluso aunque cuando el intérprete se aleje de la interpretación tradicional que de la enmienda venía haciéndose limitándola a garantías exclusivamente negativas ${ }^{24}$. Se ha subrayado también como este renovado activismo de la Corte la obligaría a recurrir a valores metajurídicos, ya no los de la «social statics» de Spencer, — en las célebres palabras de Holmes ${ }^{25}$ — sino los de la filosofía moral de Rawls ${ }^{26}$. Otros autores críticos han vuelto al clásico argumento que tiende a negar la legitimidad de la «constitutional adjudication» cuando de esa pueda derivar una interferencia con la dirección política ${ }^{27}$.

A la Corte Burger, finalmente, le faltó la voluntad de un mayor intervencionismo y la capacidad de remodelar sectores enteros del ordenamiento que hubieran sido necesarios. Se limitó a decisiones muy prudentes, artesanales, tan detalladas que desembocaron en una pluralidad de opiniones, retrasando la constitucionalización de nuevos derechos sociales cada vez que se acercaba su reconocimiento.

Por un lado, la Corte Burger siguió el camino de las restricciones de procedimiento a la acción administrativa de sujetos federales y estatales que pudieran violar la «libertad» y la «propiedad», y no simples «privilegios» que se pueden limitar con plena discrecionalidad. Por ejemplo, la Corte Suprema había prohibido la interrupción o suspensión de prestaciones de asistencia social sin formas

21 R. Dworkin, Taking Rights Seriously, Cambridge, Mass., 1977.

22 Sobre todo L.H. Tribe, American Constitutional Law, Mineola, N.Y, 1978 y Unraveling National League of Cities: The New Federalism and Affirmative Rights to Essential Government Services, 90 Harv. L. Rev. 1065 (1977); T. C. Grey, Procedural Fairness and Substantive Rights, J. Pennock (ed.), Due Process, cit. 182 y Property and Need: The Welfare State and Theories of Distributive Justice, 28 Stan. L. Rev. 877 (1976); K.L. KARST, The Supreme Court, 1977 Term-Forward: Equal Citizenship under the Fourteenth Amendment, 91 Harv. L. Rev. 1 ss. (1977).

23 R. A. Posner, Economic Analysis of Law, Boston, Mass., 1977, 503 ss.

24 H.P. Monaghan, Commentary: The Constitution Goes to Harvard, 13 C.R. - C.L.L.Rev 117 ss. (1978); R.K. WINTER, Jr., Changing Concepts of Equality: From Equality before the Law to the Welfare State, 1979 Wash. U.L. Q. 741 ss.

25 En Lochner v. New York, 198 U.S. 90 (1905, dissenting opinion).

26 R.H. Bork, Commentary: The Impossibility of Finding Welfare Rights in the Constitution, 1979 Wash. U. L.Q., 695 ss.; H.P. Monaghan, Commentary, cit., 119.

27 R.K. Winter, JR., Poverty, Economic Equality, and the Equal Protection Clause, 1972 Sup. Ct. Rev. 41; G.E. Frug, The Judicial Power of the Purse, 126 U.Pa. L. Rev. 715 ss. (1978). 
plenas de contradictorio con la parte privada, recordando que «desde su fundación la nación se ha impuesto la obligación de promover la dignidad y el bienestar de las personas que viven es sus fronteras» y que «asistencia no es sencillamente beneficencia, sino una manera de hacer posible la bendición de la libertad a nosotros y a nuestra descendencia». También ha declarado ilegítimas la revocación de pensiones de vejez sin audiencia previa, la revocación de pensiones de invalidez sin interrogar testigos de forma contradictoria, la interrupción de nuevas terapéuticas farmacológicas, la parcialidad de un informe pericial médico, el embargo parcial del sueldo de un trabajador subordinado sin darle audiencia o de bienes esenciales para asegurar una vivienda digna a la persona y a sus familiares. El punto de máxima exposición de la retórica de la Corte hacia el pleno reconocimiento de los derechos sociales fue la afirmación de Justice Stewart según la cual hay que repudiar como falsa la «dicotomía entre libertades personales y derechos», «la propiedad puede consistir en un subsidio de asistencia, un techo o una cuenta corriente» ${ }^{28}$. Esta jurisprudencia había hecho creer a muchos que una ampliación seria de las posiciones legitimadoras era inminente y que la protección del procedural due process podría conducir a la emergencia de expectativas sustanciales $^{29} \mathrm{o}$ a un concepto de new property.

Pronto una retracción gradual dejó lugar a una derrota completa. Decisiones como Board of Regents v. Roth, Bishop v. Wood, Meachum v. Fano, y muchas otras $^{30}$ han clarificado que no hay espacio para la dilatación de la protección de expectativas o entitlements de naturaleza social y que el interés privado amenazado tiene que someterse a un proceso de ponderación frente a los intereses públicos involucrados, inclusos los gravámenes financieros y administrativos.

Otra vía indirecta hacia la constitucionalización de los derechos sociales habría podido ser la equal protection clause de la XIV Enmienda bajo el perfil del control de la lógica relacional en el tratamiento por las normas legislativas de grupos o categorías de individuos en la distribución o en la medida del disfrute de intereses fundamentales. La arbitrariedad de clasificaciones legislativas según

28 Goldberg v. Kelly, 397 U.S. 254 (1970); 397 U.S. 264-5; Wheeler v. Montgomery, 397 U.S. 280 (1970); Richardson v. Wright, 405 U.S. 208 (1972); Weinberger v. Hymson, Westcott and Dunning Inc., 412 U.S. 609 (1973); Withrow v. Larkin, 421 U.S. 35 (1975); Snaidach v. Family Finance Corp., 395 U.S. 337 (1969); Fuentes v. Shevin, 407 U.S. 67 (1972); Lynch v. Household Finance Corp., 405 U.S. 538 (1972).

29 V. por ejemplo J.J. Graham, Poverty and Substantive Due Process, 12 Ari. L. Rev. 1 ss. (1970); R.M. O' NeIL, Of Justice Delayed and Justice Denied: The Welfare Prior Hearing Cases, 1970 Sup. Ct. rev. 160 ss.; Note, The Growth of Procedural Due Process into a New Substance: An Expanding Protection for Personal Liberty and a "Specialized Type of Property... in Our Economic System», 66 Nw. L. Rev. 502 ss. (1971).

30408 U.S. 564 (1972): la negativa de una universidad a contratar de nuevo a un profesor no puede ser subordinada a formalidades procedurales si la ley estatal no lo impone expresamente; 426 U.S. 341 (1976): en materia de empleo público la protección procedural necesita norma de ley; 427 U.S. 215 (1976): la traslación de un detenido a una cárcel a régimen más duro no implica sacrificio para una posición de libertad; Como Vitek v. Jones, 445 U.S. 480 (1979); Hughes v. Rowe, 449 U.S. 5 (1980); Cuyler v. Adams, 449 U.S. 433 (1981); Goss v. Lopez, 419 U.S. 565 (1975); Mathews v. Eldridge, 424 U.S. 319 (1976); Ingraham v. Wright, 430 U.S. 651 (1977) 
parámetros sensibles, como raza o condición económica, ya en la Corte Warren había sido utilizada sobre todo en el sector de la disciplina electoral y del derecho penal $^{31}$. La Corte Burger empezó su recorrido dando la impresión de aumentar el número de áreas sensibles y de criterios clasificatorios sospechosos, con especial atención al parámetro riqueza/pobreza. Por ejemplo la Corte invalidó la legislación estatal sobre los vagabundos, extendió la asistencia jurídica gratuita, vedó la sustitución de penas pecuniarias con la detención para los indigentes y la recuperación de gastos procesales o de defensa anticipadas a indigentes, ha eliminado requisitos patrimoniales para las elecciones de los distritos escolásticos y la obligación de entregar depósitos para la candidatura ${ }^{32}$. En el ámbito de los servicios sociales, invalidó el Federal Food Stamp Act para mejorar el derecho a la nutrición de las clases menos pudientes, porque excluía convivientes no ligados por vínculos de parentela o afinidad ${ }^{33}$ o miembros mayores de edad que en el año anterior habían vivido en otro núcleo familiar ${ }^{34}$; sancionó la invalidez de programas estatales de asistencia a familias con hijos ilegítimos ${ }^{35}$; utilizó el derecho a la libre circulación para evitar que la asistencia sanitaria fuese negada a aquellos que no vivieron en un Estado por un tiempo mínimo ${ }^{36}$.

Desde 1973 , si no antes ${ }^{37}$, la Corte construyó una parábola descendiente hacia la negación de la existencia de derechos sociales plenos y la afirmación de la necesidad de valorizar la estabilidad presupuestaria y los problemas financieros de los entes públicos. Por ejemplo: Ross v. Moffitt ha declarado que no existe obligación para los Estados de conceder asistencia gratuita a detenidos indigentes para apelaciones cuya proponibilidad depende de la discrecionalidad de los juzgados; United States v. Kras no ha sancionado la existencia de barreras económicas al recurso a procedimientos de quiebra; Ortwein v. Schwab también ha tolerado la presencia de obstáculos económicos a los recursos jurisdiccionales contra la denegación o la suspensión de prestaciones asistenciales o de seguridad social; Mitchell v. Grant ha atenuado las garantías del deudor en la ejecución forzosa sobre bienes de importancia primaria; en materia electoral, Salyer ha vuelto a admitir el requisito de la titularidad de propiedad inmobiliaria para la elección

31 Por ejemplo en Reynolds v. Sims, 377 U.S. 533 (1964), Harper v. Virginia Board of Elections, 383 U.S. 663 (1966), Kramer v. Union Free School District No. 15, 395 U.S. 621 (1969); como en Griffin v Illinois, 351 U.S. 12 (1956), Douglas v. California, 273 U.s. 353 (1963), Anders v. California, 386 U.S. 738 (1967), Gideon v. Wainwright, 372 U.S. 335 (1963), Miranda v. Arizona, 384 U.S. 436 (1966).

32 Papachristou v. City of Jacksonville, 405 U.S. 156 (1972); Argersinger v. Hamlin, 407 U.S. 25 (1972); Williams v. Illinois, 399 U.S. 235 (1970) y Tate v. Short, 401 U.S. 395 (1971); James v. Strange, 407 U.S. 128 (1972); Turner v. Fouche, 396 U.S. 346 (1970); Bullock v. Carter, 405 U.S. 134 (1972).

33 United States Department of Agriculture v. Moreno, 413 U.S. 528 (1973).

34 United States Department of Agriculture v. Murry, 413 U.S. 508 (1973).

35 New Jersey Welfare Rights Organization v. Cahill, 411 U.S. 619 (1973).

36 Memorial Hospital v. Maricopa County, 415 U.S. 250 (1974).

37 V. la descripción de G.F. FERrari, Localismo ed eguaglianza nel sistema americano dei servizi sociali, Padova, 1983, 399 ss. y La Corte Suprema degli Stati Uniti durante la presidenza Burger, Giur. Cost., 1987, 1896 ss. 
de órganos locales de gobierno de las aguas; Lubin v. Panish ${ }^{38}$ ha convalidado los depósitos de los candidatos siempre que no impliquen la exclusión total.

Otras decisiones han confirmado la revocación de subsidios de asistencia social a quienes no hayan acreditado la búsqueda de trabajo periódicamente, evidenciando los problemas de disponibilidad de recursos por parte del Estado, legitimado la pérdida de beneficios asistenciales en caso de emigración, avalado definiciones restrictivas del núcleo familiar para la asignación de alojamientos económicos; ha mantenido en vida una norma federal que asegura la reversibilidad de una pensión a favor del cónyuge solamente después de un período mínimo de matrimonio; ha aprobado separaciones estrictas entre zonas urbanísticas de edilicia popular y de edilicia residencial no subvencionada. Sobre todo, la Corte ha adoptado un lenguaje que no deja dudas en cuanto a su disponibilidad a utilizar un nivel de escrutinio severo o estricto en referencia a las normas en materia de servicios sociales, estableciendo, por ejemplo, que «no se encuentra en la Constitución... un remedio judicial para cualquier mal social y económico» ${ }^{39}$.

Con esta jurisprudencia parece haberse acabado la posibilidad de constitucionalizar derechos sociales tanto por la vía del procedural due process como por la de la equal protection clause. Al Congreso y a los legislativos estatales pertenece la exclusiva responsabilidad de estructurar el sistema de bienestar con amplia discrecionalidad, con la posible excepción de exclusiones groseras o de clamorosos vicios de procedimiento.

Desde entonces, la sensibilidad de la Corte Suprema para las expectativas sociales no ha crecido, sino todo lo contrario ha disminuido, aunque con oscilaciones e incertidumbres. Por ejemplo, desde el final de los ochenta ha empezado a rechazar la mayoría de los recursos en materia de asistencia y previdencia contra las agencias de regulación. La tendencia se fortifica en los noventa, aunque no falten excepciones cuando entró en juego la protección de la propiedad o se trató de definir el concepto de familia a fines asistenciales. Hacia el final de la década de los noventa se manifiesta una orientación favorable a las ayudas para los discapacitados ${ }^{40}$.

38417 U.S. 600 (1974); 409 U.S. 434 (1973); 410 U.S. 656 (1973); 416 U.S. 600 (1974); Salyer Land Corporation v. Tulare Water District, 410 U.S. 719 (1973); pero v. también Ball v. James, 451 U.S. 355 (1981); 1415 U.S. 709 (1974).

39 New York State Department of Social Services v. Dublino, 413 U.S. 405 (1972); Califano v. Gautier Torres, 435 U.S. 1 (1978); Belle Terre v. Boraas, 416 U.S. 11 (1974); Weinberger v. Salfi, 422 U.S. 749 (1975); Village of Arlington Heights v. Metropolitan Housing Development Corporation, 429 U.S. 252 (1977); Lindsay v. Normet, 405 U.S. 74 (1974).

40 Vid. Sullivan v. Everhart, 494 U.S. 83 (1990) y Sullivan v. Stroop, 496 U.S. 478 (1990); Washington v. Harper, 494 U.S. 210 (1990); Irwin v. Veterans Administration, 498 U.S. 89 (1990); Reno v. Flores, 502 U.S. 292 (1993), 508 U.S. 182(1993), Sandin v. Conner, 515 U.S. 472 (1995); Honda Motor Co., Ltd. V. Oberg, 512 U.S. 415 (1994), que impone limitaciones a los daños punitivos en favor de los consumidores; Anderson v. Edwards, 514 U.S. 143 (1995) y City of Edmond, Wash. v. Oxford House, Inc., 514 U.S. 725 (1995); Cleveland v. Policy Management Systems Corp., 526 U.S. 795 (1999); Sutton v. United Air Lines, Inc., 527 U.S. 471 (1999); Murphy v. United Parcel Service, Inc., 527 U.S. 516 (1999); Albertsons, Inc. v. 
A comienzos del nuevo siglo la Corte Suprema ha utilizado a veces la equal protection clause para la definición de la amplitud de la protección acordada por el Americans with Disabilities Act, definiendo el nivel de enfermedad necesario para gozar de ventajas ocupacionales y los poderes del empleador cuando contrata a un empleado. También ha usado la misma cláusula para la definición restrictiva del ámbito de la cobertura de pensión según el parámetro de la edad, para permitir la inaplicación de la inmunidad de los Estados de la XI Enmienda, frente a acciones civiles en cortes federales de discapacitados que pidan daños por discriminación y para limitar la reducción de financiación estatal a los distritos locales de instrucción que ya gocen de recursos federales ${ }^{41}$.

En los últimos años, la Corte Suprema no ha encontrado nuevas ocasiones para ocuparse del equilibrio entre expectativas sociales y recursos financieros. Pero ya había llegado a soluciones bastante consolidadas. Las dos cláusulas «oraculares» de la XIV Enmienda han producido resultados en campos diferentes, desde el tratamiento de las relaciones homosexuales hasta la vuelta al acercamiento «colorblind» en la coexistencia de las razas ${ }^{42}$.

\section{ALEMANIA}

El ordenamiento alemán se ha enfrentado con su tradicional y geométrica escrupulosidad a la situación de crisis económico-financiera, pese a que ha golpeado en él menos seriamente que en otros países. Los valores en juego siguen siendo la dignidad humana y la naturaleza social del Estado, consagrados en los artículos 1, 20 y 28 del GG. El equilibrio entre estos valores se busca por el Tribunal Constitucional mediante unos instrumentos elaborados en más de medio siglo de jurisprudencia.

Ante todo, en presencia de expectativas en conflicto, el juez constitucional se preocupa de definir correctamente la medida de las necesidades según el principio de efectividad real, estudiado por Habermas ${ }^{43}$. Esa valoración pertenece en

Kirkingburg, 527 U.S. 555 (1999); Olmstead v. L.C., 527 U.S. 581 (1999); Cedar Rapids Community School District v. Garret, 526 U.S. 66 (1999). En el mismo año Roberts v. Galen of Virginia, Inc., 525 U.S. 249 (1999) se ocupa del hospedaje de emergencia, Hughes Aircraft Co. V. Jacobson, 525 U.S. 432 (1999) de fondos no contributivos para jubilados, Geissal v. Moore Medical Corp., 524 U.S. 74 (1998) de la continuación del disfrute de fondos de asistencia sanitaria

41 Vid. 104 Stat. 328, 42 U.S.C. § 12101 ss; Toyota Motor Manifacturing, Kentucky Inc. v. Williams, 534 U.S. 184 (2002) y Clackamas Gastroenterology Associates PC v. Wells, 538 U.S. 440 (2003); Chevron USA Inc. v. Echazabal, 536 U.S. 73 (2002).; General Dynamics Land Systems, Inc. v. Cline, 540 U.S. 81 (2004); Tennessee v. Lane, 541 U.S. 509 (2004).; Zuni Public School District No. 89 v. 550 U.S. 81 (2007).

42 Obergefell v. Hodges, 576 U.S. _ (2015); United States v. Windsor, 570 U.S. _ (2013), 133 S.Ct. 2675 (2013); Hollingsworth v. Perry, 570 U.S. 693 (2013), 133 S. Ct. 2652 (2013); y Fisher v. University of Texas at Austin, 579 U.S. _(2016).

43 J. Habermas, Faktizität und Geltung, Beiträge zur Diskurstheorie des Rechts und des demokratischen Rechtsstaats, Frankfurt am Main, 1992.

UNED. Teoría y Realidad Constitucional, núm. 43, 2019, pp. 349-370 
primer lugar al legislador cuya discrecionalidad tanto al apreciar el alcance de las necesidades como al identificar y ponderar los medios financieros y organizativos idóneos debe ser respetado «en la medida de lo posible». El procedimiento no debe tener vicios derivados de la falta transparencia o de ponderación entre medios y fines, y debe considerar el concreto grado de desarrollo (Entwicklungsstand des Gemeinwesens) de la comunidad de referencia y de las condiciones reales de la vida (bestehenden Lebensbedingungen). Esta técnica de valoración se ha consolidado en las décadas más afortunadas de la historia del derecho constitucional alemán, y el Tribunal constitucional la ha utilizado sin variaciones en los años recientes, en particular en el célebre caso Hartz IV, de $2010^{44}$, con referencia al subsidio por desempleo (Arbeitslosengeld) y a su entidad desde comienzos de 2005.

La reforma Hartz, aprobada en 2002 y denominada según el apellido del ministro del Gobierno Schröder, antiguo director del personal de Volkswagen, — posible razón de la derrota de la SPD en 2005—, había enmendado el Código social. En concreto, la reforma había unificado el subsidio de desempleo de larga duración y el auxilio social, y afectaba a 6.7 millones de beneficiarios. Se había pues reducido el gasto social significativamente. El Tribunal Constitucional ya había declarado en parte inconstitucional en 2007 la ley Hartz IV por violación de la autonomía municipal después de la reforma constitucional de 2006, que había prohibido intervenciones federales directas en el ámbito de autonomía de los municipios. Nuevamente invitados a pronunciarse por algunos tribunales sociales en 2009 por la supuesta violación del principio de racionalidad y del mínimo vital digno, el Tribunal de Karlsruhe ${ }^{45}$ declaró correcto el modelo estadístico utilizado para la definición de los importes, pero inconstitucional su aplicación concreta, en razón de la incorporación en la «cesta de la compra» de bienes y servicios ajenos a la ratio de las intervenciones sociales. En palabras más explícitas, la reforma no tenía como objetivo una verdadera definición del mínimo vital para una existencia digna sino una reducción del gasto social.

Después de Hartz IV, el Tribunal de Karlsruhe ha vuelto varias veces a ocuparse de derechos sociales, pero bajo perfiles no directamente conectados con la emergencia económica, como por ejemplo en materia de pensiones y de salarios ${ }^{46}$.

La regla básica es de todas formas el respeto a la reserva de lo posible (Vorbehalt des Möglichen) en favor del poder legislativo, como nivel máximo exigible por ciudadanos y consumidores de servicios sociales.

44 BVerfGe, 22, 180 (224); 29, 221 (235) y varias otras decisiones. V. por ejemplo Beck's Kompakt - Kommentare, Grundgesetz, 3. Auflage, 2015, 8 ss; Y BvL 1/09, 3/09, 4/09, de 9 de febrero de 2010.

45 BVerfG, 2 Senat, sent. 20.12.2007. 2 BVR 2433/04 y 2434/04 y BVerfG 125, 175, 1. Senat, sent. 9.2.2010 - 1 BUL 1/09, 3/09, 4/09. Entre los varios comentarios, U. SARTORIUS, Verfassungswidrigkeit der Regelleistung des SGB II, Zeitschrift für die Auwaltspraxis, 2010, 279 ss.

46 BVerfG, 3 Senat, ord. 28.4.2011 y BVerfG, 2 Senat, ord. 2.5.2012- 2 BvL 5/10 y BVerfG, 2 Senat, sent. 14.2.2012-2BvL 4/10. 


\section{ITALIA}

El caso italiano presenta muchas particularidades, debido a la peculiar influencia europea en la situación financiera del país, que entre otras cosas tuvo una importancia determinante en la reforma del art. 81 de la Constitución en $2012^{47}$. Desde 2008 la Corte constitucional ha producido una jurisprudencia muy variada y fragmentaria tanto en los conflictos entre Estado y Regiones sobre temas conectados con la autonomía financiera de los entes territoriales como en materia de servicios sociales cada vez que un recurso contra leyes estatales llega a la Corte en vía principal o incidental. Si se puede hallar un motivo recurrente en esta serie de decisiones, en muchas ocasiones contradictorias, es la protección de un interés económico nacional subyacente, como instrumento de conciliación de posiciones contrapuestas; al mismo tiempo, siguiendo este leitmotiv, no se pueden sacrificar en medida excesiva ni la autonomía financiera de las autonomías territoriales ni los niveles esenciales de los derechos sociales. El equilibrio de estos valores ha llevado muchas veces a soluciones de compromiso, que no parecen satisfactorias incluso para los miembros de la misma Corte $^{48}$.

En varios casos, la Corte ha declarado inconstitucionales leyes de reparto de fondos entre los distintos niveles de gobierno, con especial referencia a la dotación de solidaridad municipal por falta de participación en el procedimiento decisorio de la Conferencia Estado-Regiones-Ciudades ${ }^{49}$. Por otro lado, incluso si se llega a un acuerdo en la Conferencia, los intereses de una Región o Provincia autónoma no pueden ser perjudicados por la mediación conseguida en el órgano colegial de la Conferencia ${ }^{50}$.

La referencia del legislador al contexto financiero o a las condiciones de la crisis no es suficiente para justificar un sacrificio irrazonable para categorías vulnerables, por ejemplo, la Corte ha rechazado un decreto-ley dirigido a conseguir un recorte de pensiones, cuya conversión en ley no daba cuenta en detalle de los criterios técnicos adecuados. En el caso de la anticipación de la jubilación de los profesores universitarios, en cambio, una relación técnica utilizada incluía un cuadro analítico de proyección dentro de un decenio de los datos concernientes el ahorro para la Hacienda pública frente a la mayor erogación de liquidaciones de indemnizaciones por el fin de contrato a los jubilados ${ }^{51}$.

47 Vid por ejemplo D. Morgante, La costituzionalizzazione del pareggio di bilancio, federalismi.it, julio 2012; C. Tucciarelli, Pareggio di bilancio e federalismo fiscale, Quad. cost., 2012, 799 ss.; D. CABRAs, La legge di attuazione del principio costituzionale del pareggio di bilancio, Quad. cost., 2013, 124 ss.; A. Morrone, Pareggio di bilancio e Stato costituzionale, Rivista AIC, 2014, n.1.

48 Vid por ejemplo A. CAROsI, La Corte costituzionale tra autonomie territoriali, coordinamento finanziario e garanzia dei diritti, Rivista AIC, 4/2017.

49 Corte Constitucional, 129/2016.

50 Corte Constitucional, 187/2011 y 169/2017.

51 Corte constitucional, 70/2015 y 133/2016. 
La mera irracionalidad del recorte financiero raramente es suficiente para llegar a la conclusión de la inconstitucionalidad de una ley, pero puede pasar que la naturaleza impredecible de una trasferencia de fondos sea suficientemente importante para justificar un pronunciamiento de inconstitucionalidad. En un caso de servicio de asistencia a discapacitados cofinanciado por una Región y varias Provincias, la variación demasiado significativa de la contribución regional a lo largo de los años determinó una sentencia estimatoria ${ }^{52}$; en otros casos, un recorte imprevisto del $80 \%$ de las transferencias regionales para servicios sociales a las Provincias pareció irrazonable y por lo tanto insoportable ${ }^{53}$.

Otra contribución de la jurisprudencia constitucional italiana al problema del balance entre derechos sociales y emergencia financiera ha sido la posibilidad de no limitarse a la antigua distinción entre decisiones estimatorias o desestimatorias o aditivas de gasto público, sino introducir en las sentencias vínculos financieros al legislador mediante «pronunce monitorie» — que formulan avisos- encaminadas a la recuperación del equilibrio económico, financiero y patrimonial junto al restablecimiento de la plena protección de los derechos sociales injustamente sacrificados. Se habla de un equilibrio dinámico para describir el margen de discrecionalidad dejado al legislador para que ponga remedio en tiempo a los perjuicios a la solidaridad social sin efectuar su intervención de manera insostenible para las finanzas públicas $^{54}$. En esta forma se ha evitado que a la mera advertencia no sigan acciones concretas de ejecución, como pasaba bastante a menudo en años anteriores ${ }^{55}$, pero, al mismo tiempo, la Corte no se ha transformado en un legislador positivo, que prescriba a las asambleas parlamentarias fechas, asignaciones de sumas y otra medidas puntuales ${ }^{56}$.

Hay que subrayar también que una de las soluciones a las tenciones entre entes territoriales y Estado en los derechos sociales podría haber sido la aplicación de la ley 42/2009, llamada de federalismo fiscal, que prometía una redistribución de recursos conforme al artículo 119 de la Constitución a través de una correspondencia más adecuada de recursos a funciones y su redistribución conforme a criterios de eficiencia y racionalidad ${ }^{57}$. El eje del sistema habría sido el cálculo de costes y necesidades estándar, con los que medir la eficiencia de cada administración local

52 Corte constitucional, 275/2016.

53 Corte constitucional, 188/2015 y 10/2016.

54 Corte constitucional, 213/2008, 259 y 266/2013, 40/2014, 10/2015, 155/2015.

55 Por ejemplo, a la «pronuncia monitoria» que amenazaba la posible incostitucionalidad del bloque de las pensiones (sent. 316/2010) había dejado el paso al acogimiento en la sentencia 70/2015 por falta de iniciativas por parte del legislador. Se habla en esos casos de «esterilización financiera» de las decisiones de la Corte.

56 Hay muchísima doctrina sobre esta solución: F. Bilancia, Spending review e pareggio di bilancio, Dir. Pubbl., 2014, 58 ss.; M. LuCIAnI, Diritti sociali e livelli essenziali delle prestazioni pubbliche nei sessant'anni della Corte costituzionale, Rivista AIC, 3/2016, 9 ss.

57 V. por ejemplo G.F. Ferrari, Il federalismo fiscale all'inizio della XVII legislatura, en Idem (Ed.), Lo stato della finanza locale in Italia e in Europa, Venezia, 2013, 16 ss. 
en la erogación de servicios públicos ${ }^{58}$. El proceso de ejecución de esta ley se interrumpió en noviembre de 2011 con las medidas impuestas por la Unión Europea; desde el Gobierno Monti hasta ahora solo se han aplicado cortes lineales a los gastos, con efectos inmediatos para la Hacienda pública, pero con la perpetuación de injusticias distributivas históricas.

En perspectiva diacrónica se puede decir que en los años setenta la Corte se comprometió abiertamente a extender el sistema de seguridad social, con la necesaria gradación ${ }^{59}$, favoreciendo la elevación de los niveles de igualdad y la eliminación de posibles privilegios. En la siguiente década la Corte se dio cuenta de las restricciones financieras y descubrió que la igualdad no es siempre unidireccional, sino que puede moverse hacia abajo, con el desconocimiento del tertium comparationis. En los noventa el equilibrio financiero entró en los ejercicios de ponderación, con posibilidad de producir resultados diferentes en el tiempo ${ }^{60}$. En el nuevo siglo la Corte se hizo cargo de los límites objetivos que el legislador encuentra en la disponibilidad de recursos financieros y organizativos, sin que se pueda abdicar de golpear las discriminaciones entre categorías de sujetos, que siguen imponiendo sentencias aditivas ${ }^{61}$.

\section{FRANCIA}

En el derecho constitucional francés el control de constitucionalidad queda limitado por los artículos de la Constitución de 1958 que lo disciplinan ${ }^{62}$. Las normas sobre los derechos sociales en el Preámbulo de la Carta de 1946, en varios párrafos entre el quinto y el undécimo, aunque forman parte del «bloc de constitutionnalité», no pueden fácilmente ser utilizadas como vía para la declaración de inconstitucionalidad de leyes. Las raíces en la solidaridad revolucionaria de la

$58 \mathrm{La}$ Corte ha lamentado el retraso en el completamiento de este proceso, avisando que en su ausencia no se puede pensar que el precepto constitucional sea programático ni que el equilibrio financiero pueda condicionar la medida de la satisfacción de los derechos no comprimibles (sentencias 275/2016 y 169/2017).

59 Como por ejemplo en las sentencias $126 / 1977$ y $128 / 1973$.

60 Corte constitucional, 455/1990, 247/1992, 304/1994, 267/1998.

61 Corte constitucional, 200/2005 y 476/02 y 28/2009. Sobre esta evolución M. Midiri, Giurisprudenza, tutela dei diritti, vincoli di bilancio, Contratto e impresa, 2011, 996 ss. Entre la extensa doctrina reciente citable, merece mencionar por lo menos A. SAITTA, Fiscal Compact tra Costituzione trattati e politica, Rivista AIC 4/2017; L. ANTONIni, La Corte costituzionale a difesa dell'autonomia finanziaria: il bilancio è un bene pubblico e l'equilibrio di bilancio non si persegue con tecnicismi contabili espropriativi, Rivista AIC 1/2018; M. LuCIANI, La giurisprudenza costituzionale nel tempo della crisi, in M. D'Amico, F. BIONDI, Diritti sociali e crisi economica, Milano, 2017, 15 ss.; Idem, Diritti sociali e livelli essenziali delle prestazioni pubbliche nei sessant'anni della Corte costituzionale, in Per i sessant'anni della Corte costituzionale, Milano, 2017, 121 ss.; antes G. Romeo, La cittadinanza sociale nell'era del cosmopolitismo: uno studio comparato, Padova, 2012.

62 V. por ejemplo F. Hamon, M. Troper, Droit constitutionnel, $38^{a}$ éd., París, 2017, 785 ss.; M.-A. COHEndet, Droit constitutionnel, 3. ${ }^{a}$ ed., 2017, 647 ss.; J. GiCQUel, J.-É. GICQUEL, Droit constitutionnel et institutions politiques, 31. ${ }^{\text {e }}$ ed., 2017, 83 ss. 
Carta de $1795^{63}$ no han contribuido a lograr el pleno reconocimiento de los derechos sociales. La idea compartida por la casi totalidad de los autores ${ }^{64}$ es que la pobreza tiene causas sociales y debe poseer remedios de carácter económico, y que los derechos sociales sean instrumentos de transformación social y corrección del liberalismo económico, pese a que no sean formalmente accionables ante los tribunales, independiemente de que se trate del Conseil Constitutionnel (según el art. 61 de la Constitución vigente), del Consejo de Estado o de los tribunales administrativos. El primero afirma constantemente que las normas del Preámbulo de 1946 imponen la creación de servicios públicos, dejados a la discrecionalidad del poder legislativo ${ }^{65}$, que solo está obligado a realizar los objetivos de solidaridad, sin que el Conseil pueda revisar las decisiones del Parlamento, sobre todo cuando impliquen un considerable esfuerzo financiero.

El carácter positivo y legalmente vinculante de los derechos sociales (droits-creánces) no está en duda, pero no alcanza el nivel de la plena justiciabilidad, calificándose como objetivo constitucional ${ }^{66}$. Cuando el Conseil tiene que evaluar la importancia de un derecho social, se preocupa ante todo de que este derecho no comprima o frene de una manera no necesaria o desproporcionada otros derechos; pero luego puede ocuparse de asegurar que la medida legislativa bajo examen no deje el derecho social sin suficientes garantías legales ${ }^{67}$, es decir, que no anule su eficacia. Si bien nunca se ha dado una definición de contenidos mínimos.

Tampoco está claro si, en presencia de un objetivo constitucional, el legislador pueda bajar el nivel de calidad o cantidad de un servicio social, como a veces parece haber afirmado («effet cliquet»), o si, por el contrario, una regla con este contenido no existe.

Es pacífico, sin enbargo, según el Conseil, que un error manifiesto debido al traslado de los flujos financieros, en perspectiva temporal, desde las previsiones legislativas pueda conducir a la declaración de inconstitucionalidad ${ }^{68}$.

El Consejo de Estado, por su parte, puede comprobar la legitimidad de actos administrativos específicos contrarios a normas legislativas o reglamentarias que

63 M. Bongetto, La fraternitée en droit public français, París, 1993.

64 Desde el clásico G. Burdeau, Traité de science politique, t. VI, 465, La démocratie gouvernante, París, 1956, a D. Roman, Le droit public face à la pauvreté, Paris, 2002.

65 V. por ejemplo decisiones n. ${ }^{\circ} 2008-569,21$ de agosto de 2008; n. ${ }^{\circ} 2007-553$, de 3 de marzo de 2007; n. ${ }^{\circ}$ 96-387 de 21 de enero de 1987.

66 B. Mathieu, M. Verpaux, Contentieux constitutionnel des droits fondamentaux, LGDJ, 2002, 425 ss.; M.P. Deswarte, Droits sociaux et État de droit, RDP, 1995, 975 ss.; D. Roman, La justiciabilitè des droits sociaux ou les enjeux de l'édification d'un État de droit social, Rev. des droits de l'homme, 2012, 9 ss.; V. CHAMpeil-Desplats, D. LochaK (dir.), A la recherche de l'effectivité des droits de l'Homme, Paris, 2008; Droits des pauvres, pauvres droits? Recherche sur la justiciabilitè des droits sociaux, Paris, 2010, 6 ss.

67 Como en las decisiones n. ${ }^{\circ} 83-156$, de 13 de enero de 2000 (reducción del horario de trabajo contra libertad de empresa) o $n^{\circ} 90-283$, de 8 de enero de 1991 (derecho a la salud contra libertad de empresa); o como en la sentencia n. ${ }^{\circ} 2003-483$, de 14 de agosto de 2003.

68 Sentencias n. ${ }^{\circ} 84-181$, de 11 de octubre de 1984 y 2001-456, de 27 de diciembre de 2001. 
prevén la prestación de servicios públicos o incluso evaluar violaciones de principios del Preámbulo por normas reglamentarias, siempre que no constituyan aplicación directa de una ley. En ningún caso, todavía, puede inaplicar o anular actos únicamente por contraste con derechos sociales ${ }^{69}$. La doctrina especializada, de hecho, como los manuales de derecho de la protección social, ni siquiera mencionan posibles tensiones en lo contencioso administrativo entre expectativas sociales y limitaciones financieras ${ }^{70}$.

\section{ESPAÑA}

La doctrina española ha dedicado sus mejores energías a la naturaleza jurídica, la eficacia, el contenido y la la protección de los derechos sociales desde los primeros años de vigencia de la Constitución ${ }^{71}$. Este interés fue fruto de la casi absoluta novedad de las previsiones constitucionales contenidas en las Cartas del ciclo constitucional de los años setenta y, entre otras cosas, de la casi contemporánea crisis energética que bloqueó el desarrollo económico de las democracias occidentales, creó serios problemas a la satisfacción de los derechos económico-sociales de prestación —o por lo menos de los niveles alcanzados en los años anteriores - y puso en riesgo el mismo modelo del Estado del bienestar, favoreciendo el advenimiento de las teorías neo-liberales todavía dominantes. Por lo tanto, al llegar la nueva y aun más grave, crisis económica de 2008, el derecho público español no fue sorprendido por las restricciones presupuestarias impuestas tanto por factores internos como por las presiones de la Unión Europea, aúnque su impacto sobre la administración prestacional haya sido muy fuerte ${ }^{72}$.

En los primeros años de la crisis, es decir entre 2007 y 2010, los problemas del derecho constitucional de la crisis se presentaron en forma de tensiones entre el Estado y los entes territoriales. Mientras que en Italia el problema ha sido la disminución de los recursos financieros transferidos a los entes territoriales para servicios sociales, en España, en cambio, se planteó el problema de los Estatutos de Autonomía a través de los cuales las Comunidades Autónomas intentaron

69 V. algunos ejemplos en L. PECH, Rethinking «Droits-Créances», M. LANGFORD, Social Rights Jurisprudence, cit., 267 ss.

70 V. por ejemplo F. Kessler, Droit de la protection sociale, Paris, 6. ${ }^{a}$ ed., 2017 y M. Borgetto, R. LAFore, Droit de l'aide et de l'action sociales, Paris, 8. ${ }^{a}$ ed., 2014.

71 Vid. por ejemplo E. García De EnTerría, La Constitución como norma y el Tribunal Constitucional, Madrid, 3. ${ }^{a}$ ed., 1983; J.L. CASCajo CaSTro, La tutela constitucional de los derechos sociales, Madrid, 1988; A Garrorena Morales, El Estado español como Estado social y democrático de derecho, Madrid, 1994; J. JimÉnez CAmpo, Derechos fundamentales. Concepto y garantías, Madrid, 1999, 121 ss.; E. CARmona CuenCA, El Estado social de derecho en la Constitución, Madrid, 2000.

72 Los efectos de la crisis están analíticamente descritos en el Informe conjunto al Comité de derechos económicos, sociales y culturales, Madrid, marzo 2018. Las políticas de austeridad fiscal han empezado en 2010 y se han agudizado en 2012, con un creciendo de recortes al gasto social 
introducir verdaderos derechos sociales, ante la necesidad de enriquecer las prestaciones sociales concedidas según los parámetros nacionales. El Tribunal Constitucional detuvo esta tendencia con dos famosas sentencias, muy comentadas por los constitucionalistas ${ }^{73}$, aclarando que los Estatutos no pueden crear nuevos derechos subjetivos, sino poner objetivos o directrices, y tampoco pueden calificar como verdaderos derechos fundamentales los derechos sociales reconocidos en sus Estatutos, sino solamente atribuir mandatos de actuación a los poderes públicos.

Después de la reforma del art. 135 CE, finalizada a la incorporación de los principios relativos a la estabilidad presupuestaria ${ }^{74}$, el Tribunal Constitucional ha vuelto a ocuparse, en la STC 134/2011, del equilibrio entre Estado y Comunidades Autónomas en relación a leyes de $2001^{75}$, confirmando su anteriores resoluciones según las que el Estado puede introducir limitaciones al gasto de las administraciones públicas, incluso autonómicas, pero igualmente precisando que estas exigencias presupuestarias no producen aumento alguno de las competencias del Estado ${ }^{76}$.

Después de 2010, en la fase más aguda de la crisis, el Gobierno español empezó a adoptar medidas bastante drásticas principalmente con referencia al gasto sanitario, asumiendo que el consumo de medicamentos en el país era demasiado alto ${ }^{77}$. El Real Decreto Ley n. ${ }^{\circ} 16 / 2012^{78}$, por un lado, reintrodujo el seguro como requisito para el disfrute de las prestaciones sanitarias, reduciendo la cobertura universal del Sistema Nacional de Salud y excluyendo los extranjeros sin autorización de residencia y, por otro lado, impuso el pago o copago de varias prestaciones y aportaciones dinerarias a los pensionistas. El Defensor del Pueblo

73 La STC 247/2007, de 12 de diciembre, sobre el nuevo EA de Valencia, y la 31/2010, de 28 de junio, sobre el nuevo EA de Cataluña. V. por ejemplo F. López MENUDO, Los derechos sociales en los Estatutos de autonomía, en AEPDA, Derechos sociales y Estatutos de Autonomía, Valladolid, 2009, 13 ss.; J.L. CARro FernánDeZ-VAlmaYor, L.M. Macho, Servicios sociales y crisis económica: los límites del Estado asistencial, ibidem.

74 Véase V. Ruiz Almendral, Estabilidad presupuestaria y reforma constitucional, Rev. esp. der. europeo, 2012, n. ${ }^{\circ} 41$; J. GarCía RoCa, M.A. MARTÍNEz LAGO, Estabilidad presupuestaria y consagración del freno constitucional al endeudamiento, Madrid, 2013. Más recientemente, E. ARANDA Álvarez, Derecho constitucional económico: estabilidad presupuestaria y derechos sociales, RDP, 2017, 883.

75 Mas precisamente la Ley 18/2001, de 12 de diciembre, general de estabilidad presupuestaria y la LO 5/2001, de 13 de diciembre, de modificación de la LOFCA.

76 Un comentario analítico en T. De LA QuADRA-SALCEDo JANINI, La incidencia de la reforma del artículo 135 de la Constitución sobre el Estado autonómico, Informe CC. AA., 2016, $77 \mathrm{ss}$. Del mismo autor El Estado autonómico social y el efecto de irradiación de los derechos sociales sobre el modelo constitucional de distribución de competencias, RGDA, 46, 2017.

77 V. J.J. Ruiz RuIz, El derecho a la salud en la actual crisis económica; los límites constitucionales a los recortes de prestaciones sanitarias y las exigencias de sostenibilidad del gasto social, en Dossier DPCE, VI, Diritti social e crisi economica, Ed. S. Gambino, Turín, 2015 y G.G. Carboni, La risposta della Spagna alla crisi: economia e istituzioni scelgono la strada delle riforme costituzionali, en G. Cerrina Feroni, G.F. Ferrari, Crisi economico-finanziaria e intervento dello Stato. Modelli comparati e prospettive, Turín, 2012, 211 ss.

78 Véase J. Picatoste, I. Picatoste, M.A. López Arranza, Las políticas públicas de austeridad: efectos del Real Decreto-Ley 16/2012, de 20 de abril en España, Cizur Menor, 2016. 
denunció la violación del principio de universalización, y el Tribunal Constitucional pronunció algunas importantes sentencias. En resumen, el Tribunal admitió la posibilidad de que algunas prestaciones que no son básicas, sino suplementarias o accesorias, «pueden estar sujetas a una financiación adicional con cargo al usuario del servicio» ${ }^{79}$; pero también afirmó que las Comunidades Autónomas «podrán, respetando el mínimo formado por las carteras comunes, establecer servicios adicionales para sus residentes. Es decir ... podrán mejorar el mínimo estatal, pero en ningún caso empeorarlo» ${ }^{80}$. Como contrapartida, las Comunidades Autónomas no pueden introducir tasas «sobre prestaciones sanitarias que, de acuerdo con el marco básico estatal, ... deben ser de financiación pública o estar, en su caso, sólo parcialmente sujetas a aportaciones adicionales del usuario, sin que pueda repercutirse su coste íntegro a los prestatarios del servicio» ${ }^{81}$.

En 2012, otra STC confirmó, con varios votos disidentes, varias disposiciones de la Ley n. ${ }^{\circ} 3$ del mismo año, que había introducido medidas urgentes en materia de mercado laboral. En este caso, el Tribunal Constitucional no encontró violaciones ni del derecho al trabajo (art. $35 \mathrm{CE}$ ), ni de los derechos de asociación sindical y de negociación colectiva (arts. 28.1 y 37 CE). La justificación de las medidas se encontraba en la emergencia ecónomica, que permitía al Estado un amplio margen de apreciación y la posibilidad de introducir condiciones laborales más flexibles ${ }^{82}$.

No tienen directa conexión con la tensión entre derechos sociales y recursos financieros las sentencias de los años 2013 y $2014^{83}$, que se refieren a la pensión de viudedad, en las que el Tribunal declara la constitucionalidad de varias condiciones para su disfrute, y considera razonable, según el principio constitucional de igualdad, el ejercicio de la libertad de configuración normativa del legislador.

En los años siguientes, el Tribunal Constitucional se ocupó en otras ocasiones de varios Decretos-Ley en materia de servicios sociales ${ }^{84}$, por medio de sentencias como son las SSTC 49/2015, y 26 y 139/2016. En todos los casos el Tribunal estableció que los derechos sociales, como principios rectores, no tienen contenido esencial, de manera que no pueden ser afectados por la legislación de urgencia, no afrontando, por lo tanto, las cuestiones centrales del asunto ${ }^{85}$. Por

79 STC 136/2012 de 19 de junio. En el mismo sentido STC 22/2012, de 16 de febrero.

80 STC 84/2014, de 29 de mayo, y 71/2014, de 6 de mayo.

81 STC 136/2012, cit. V. J. ToRnos MAs, Derechos sociales, comunidades autónomos y crisis económica, VI Foro de la Autonomía, 2017, 59.

82 Véase por ejemplo el comentario de I. GARcía - Perrote, La constitucionalidad de la reforma laboral de 2012. Comentario a la STC8/2015, de 22 de enero, REDC, 2015, 239.

83 Como las SSTC 41/2013, de 14 de febrero y 92/2014, de 10 de junio.

84 Como el 16/2012 relativo al Sistema Nacional de Salud, el 14/2012, de 20 de abril, de medidas urgentes en ámbito educativo, el 28/2012, de 30 de noviembre, de medidas de consolidación y garantía del sistema de la Seguridad Social.

85 V. por ejemplo M. Hernández Ramos, La respuesta del Tribunal Constitucional a los Decretos-Leyes en materia de derechos sociales. El criticable retroceso de la jurisprudencia constitucional, RVAP, 2017, 119. 
ejemplo, en materia de salud (art. 43 de la Constitución), el Tribunal consideró que, por su ubicación sistemática (Capítulo tercero de la Constitución, que contiene los «principios rectores» de la política social y económica), «el art. $43 \mathrm{CE}$ se configura como un principio rector, razón por la que carece de contenido constitucionalmente esencial que pueda ser afectado por la legislación de urgencia» (STC 139/2016).

En presencia de este nuevo equilibrio entre derechos sociales y medidas de reducción del gasto financiero, la doctrina volvió a hacerse preguntas que parecían superadas desde hace mucho tiempo. Por ejemplo, si es posible pensar en una «reserva de lo posible» como la doctrina alemana ${ }^{86}$; si hay que «explorar nuevas vías de satisfacción de los derechos socioeconómicos de prestación» ${ }^{87}$; si «la vieja construcción doctrinal civilista de los derechos adquiridos» puede «servir para fundamentar una irreversibilidad o un blindaje de los derechos de prestaciones sociales ya consolidados ${ }^{88}$ o si por lo menos se pueden emplear los principios del Estado social de Derecho y de proporcionalidad y el valor de la dignidad humana para llegar a la "prohibición de insuficiencia» de las prestaciones ${ }^{89}$; hasta si es posible recuperar la democracia pluralista y relativizar la normatividad de la Constitución ${ }^{90}$.

\section{PORTUGAL}

El ordenamiento portugués también ha conocido el constitucionalismo de la crisis. Los derechos sociales encontraron serios problemas, sobre todo cuando la Troika condicionó las ayudas financieras concedidas a la realización de medidas de fuerte impacto para contener el gasto, incluidas en el Programa de estabilidad y crecimiento (PAEF). En aplicación de este plan, la Lei de Orçamento del Estado de 30 de diciembre de $2011^{91}$ suspendió el pago de las mensualidades decimotercera y decimocuarta de funcionarios públicos y pensionistas de importe superior a 600 euros. El Tribunal Constitucional abordó el texto de esta ley con el Acórdão 353/2011, publicado a principios de julio de 2012.

86 V. por ejemplo L.E. Delgado Del Rincón, El Estado social y la fragilidad de los derechos sociales en tiempos de crisis económica, Estudios de Deusto, 2013, 43 ss.; J. García RoCa, Constitutional Principles Regarding the Spanish Social Security System: A Citizen's Right, RDP, 2014, 65, 83

87 Como J.L. Carro Fernández-Valmayor, L. Miguez Macho, Servicios sociales y crisis económica, cit.

88 J.J. Ruiz Ruiz, El derecho a la salud, cit., 739 ss.

89 Ibidem, 740.

90 Como F. Balaguer Callejón, Una interpretación constitucional de la crisis económica, RDCE, 2013, 449 ss. Otros enfoques generales, por ejemplo, M. GONZÁlez PASCUAL, Constitución española y gobernanza económica europea: desnudez y crisis del Estado constitucional, RVAP, 2017, n. ${ }^{\circ}$ 109-II, 21 y Eadem, Austerity Measures and Welfare Rights: The Spanish constitutional system under pressure, EJSL, 2014, n. ${ }^{\circ} 1-2$.

91 64-B/2011. 
La decisión, adoptada por mayoría de nueve contra tres, no desconoce la necesidad de tener en cuenta el equilibrio financiero y la eliminación del déficit. Sin embargo, afirma que los derechos sociales fundamentales, como el derecho a una existencia digna (art. 59.1 de la Constitución) y el principio de la responsabilidad estatal en la promocción de un adecuado estándar de vida para los ciudadanos (art. 9) no pueden ser sacrificados hasta el 14.3\% de la retribución anual sin violar el principio di igualdad (art. 13) entre el trabajo privado y el público, porcentaje aún más relevante en situación de crisis, y también el principio de proporcionalidad (art. 2, 18.2, 19.8, 266.2, 272.2). Por otro lado, el Tribunal asume la tarea de la modulación en el tiempo de los efectos de la pronuncia, como consentido por el art. 282.4 de la Carta constitucional, al disponer la aplicación de la sentencia a partir del año 2013, para no afectar la substancia del acuerdo financiero europeo.

El Acórdão 353/2011 fue el más importante, pero no el único del periodo de la crisis financiera. La medida de los recortes de pensiones ya había formado objeto de otro Acórdão, el 188/09, en el que el Tribunal declaró no violados los principios de igualdad, proporcionalidad y confianza en referencia a una ley que impuso límites máximos a las pensiones, con impactos más sensibles para aquellos que planeaban jubilarse en los sucesivos siete años, es decir los más ancianos y próximos a jubilarse. La motivación estaba basada en los principios de justicia intergeneracional y de sostenibilidad: las expectativas de los interesados se habían formado en presencia de exigencias de equidad contributiva y persistencia del sistema.

Un nuevo Acórdão, el 396/2011, rechazó la acción de inconstitucionalidad contra otro recorte entre $3.5 \%$ y $10 \%$ de las retribuciones de dependientes públicos superiores a los 1.500 euros. En este caso el Tribunal consideró más importantes las razones de la coyuntura económica excepcional y de la estrategia global delineada a nivel europeo, en ausencia de una absoluta garantía de irreductibilidad de los salarios. Igualmente el Acórdão 399/2010 consideró admisible el aumento de las tasas del impuesto directo sobre la renta en ausencia de una violación del principio de irretroactividad fiscal y de la «proteç̧ao de confiança».

Después de 2012, sin embargo, la jurisprudencia constitucional, tal vez como consecuencia de la superación de la fase más aguda de la crisis o de la repetición de medidas de gran impacto, revirtió la tendencia bastante radicalmente en favor de los derechos sociales. El paquete de «Acórdãos de austeridade», también llamados «Acórdãos orçamentais», dedicado a las leyes de presupuestos de los años 2013 y 2014 (187/2013 y 413/2014), con motivaciones superabundantes y extremadamente fragmentadas, utiliza el principio «da proteção da confiança» (similar al principio del Estado de Derecho democrático del art. 2 CRP), el derecho a la retribución proporcionada (art. 59.1 CRP), el derecho a la seguridad social (art. 63), la responsabilidad estatal de promover un adecuado estándar de vida en beneficio de los ciudadanos (art. 9), los principios de igualdad y proporcionalidad (art. 2 y 13), y, incluso, la regla de anualidad del presupuesto estatal 
(art. 105.2). El resultado fue la inconstitucionalidad de la supresión total o parcial del pago de las vacaciones no disfrutadas, recortes de las retribuciones a los trabajadores empleados en actividades de enseñanza o de investigación, recorte del «subsídio de férias» de jubilados y «reformados», reducción entre 5 y $6 \%$ de los subsidios de desempleo y enfermedad ${ }^{92}$.

La única decisión de los últimos tres años es el Acórdão 574/2014, relativa a un recorte de salarios de los dependientes de empresas de capital mayoritariamente público, que el Tribunal constitucional juzgó no contrastante con el principio de proporcionalidad (proibição do excesso) ni con el principio de igualdad. Esta sentencia, muy criticada en doctrina, parece una vuelta a lo antiguo, como si la crisis fuera algo del pasado.

\section{ALGUNAS CONCLUSIONES}

La crisis económica más grave de los últimos cien años ha puesto a prueba los sistemas de bienestar de los Estados democráticos, cuyo equilibrio se basa tradicionalmente en los servicios sociales y en su capacidad para consolidar el consenso social. Los países del sur de Europa fueron los primeros en acusar el golpe y en ser obligados a adoptar medidas, a menudo dolorosas e impopulares, capaces de golpear grandes segmentos de la ciudadanía, poniendo en riesgo el consenso en las propias bases del Estado social. La capacidad de absorber los efectos de la crisis dependió en parte de la solidez de los diferentes modelos de bienestar ${ }^{93} \mathrm{y}$, en todo lo demás, de variables de naturaleza económica, como son el tamaño de la deuda pública, la estructura del empleo y su distribución entre el sector privado y el público. Los recortes de los derechos sociales fueron inevitables y se repitieron en sucesivas oleadas

Era inevitable la participación de los Tribunales Constitucionales y Supremos, en muy poco tiempo, en la revisión de las decisiones gubernamental o de los legisladores sobre recortes y sacrificios a menudo muy importantes. Esta jurisprudencia del constitucionalismo de la crisis nos ha permitido, de algún modo, ubicarnos en una perspectiva genuinamente comparatista, para evaluar los diferentes enfoques adoptados y los métodos de argumentación, sus afinidades indiscutibles, pero también sus fuertes diferencias.

La Corte Suprema de los Estados Unidos ya había superado, desde principios de los años setenta del siglo pasado, líneas jurisprudenciales que se movían en el

92 Una descripción analítica de las decisiones citadas así como de otras de interés en A. CiammariCONI, R. ORRù, Vicende e attività del Tribunal constitucional portoghese nel biennio 2013-2014, Giur. Cost. 2015, 1883 ss. V. también M. González Pascual, Constitutional Courts before Euro-crisis Law in Portugal and Spain: A comparative prospect, Rev. el. direito púb., 2017, 111

93 V. la clasificación de P. Flora, A.J. Heidenheimer, The Development of Welfare States in Europe and America, New Brunswick, N.J., 1981; J. Alber, Vom Armenhaus zum Woblfahrtstaat. Analysen zur Entwicklung der Sozialversicherung in Westeuropa, Frankfurt a.M., 1982. 
sentido del reconocimiento tímido de verdaderos social rights. Por lo tanto, no tuvo que pasar una prueba demasiado difícil. La principal decisión de este ciclo jurisprudencial fue, por lo tanto, la resolución sobre el Obamacare, en muchos aspectos casi independiente del elemento de la crisis, al ser vinculada al sistema de relaciones entre los dos niveles de gobierno. La Corte limitó los poderes de la Administración Federal de penalizar a los Estados contrarios a extender Medicaid, teniendo en cuenta que el Congreso no tiene la autoridad para ordenar a las entidades federitivas para que ejecuten las previsiones del Obamacare.

Como se ha visto, la Corte Suprema británica mantuvo una actitud ajena a los esquemas ideológicos, confirmando la jurisprudencia tradicional sobre la review of administrative action y absorbiendo las tensiones recientes, según el más clásico continuismo.

El Tribunal Constitucional alemán, que ya tenía instrumentos exegéticos muy refinados, los aplicó de una forma muy pragmática, empleando la teoría de la reserva de lo posible en contextos concretos de carácter, en gran medida, federal.

El Conseil constitutionnel, seguido como siempre por el Consejo de Estado, ha fluctuado prudentemente entre la no accionabilidad de los droit-creánces y la posibilidad de reconocer y sancionar errores manifiestos de soporte técnico y de recogida de datos de la ley o en el cálculo en materia de beneficios de solidaridad.

Los jueces constitucionales de España y de Italia han abordado la cuestión de los derechos sociales principalmente desde el punto de vista de la relación Estado/ Comunidades Autónomas-Regiones, intentando desarrollar equilibrios aceptables entre la reducción de los recursos financieros disponibles para las políticas de bienestar y el sistema autonómico. El Tribunal Constitucional portugués siguió el ejemplo de estos dos tribunales, pero fue forzado, por el menor nivel de descentralización del sistema constitucional, a abordar más directamente el contenido de las opciones legislativas.

En este contexto no es posible formular conclusiones más específicas. Las convergencias entre los jueces supremos de los ordenamientos constitucionales más importantes de Occidente son más relevantes desde el punto de vista metodológico que desde un enfoque sustantivo. Una verificación inductiva de las diversas situaciones en los estados analizados confirma lo que era posible quizás predecir a partir de un juicio sintético a priori. Este es un ejemplo de cómo el método comparado no se puede definir de una vez por todas en abstracto, sino que se debe adaptar de vez en cuando de acuerdo con el tipo de temas tratados.

$$
* * *
$$

TITLE: Social rights in the constitutionalism of the crisis: a comparative perspective

ABSTRACT: The article addresses, in a comparative perspective, the ways in which the last economic crisis has been reflected in the treatment of the social rights system of some western States. The examination of the experiences, with special reference to the role of jurisprudence, of the legal systems considered shows that each 
State has responded to the effects of the crisis, in terms of social rights, according to its national characteristics. For example, where there is a strong conflict between local authorities and the State, the issue of social rights has been crossed with territorial issues. The peculiarities derived from the different methods of judgment of the constitutional and supreme courts also emerge clearly.

RESUMEN: El artículo aborda, en una perspectiva comparada, las formas en que la última crisis económica se ha reflejado en el tratamiento del sistema de derechos sociales de algunos Estados occidentales. El examen de las experiencias, con especial referencia al papel de la jurisprudencia, de los sistemas jurídicos considerados muestra que cada Estado ha respondido a los efectos de la crisis, en materia de derechos sociales, en función de sus características nacionales. Por ejemplo, donde hay un fuerte conflicto entre las autoridades locales y el Estado, la cuestión de los derechos sociales se ha cruzado con la territorial. También emergen las peculiaridades derivadas de los diferentes métodos de juicio de los Tribunales constitucionales y supremos.

KEY WORDS: Social rights, Welfare State, Economic-financial crisis, Redistribution of resources, Legal comparison, Justiciable rights, Constitutional justice, Public finance, Constitutionalism of the crisis.

Palabras Clave: Derechos sociales, Estado del bienestar, Crisis económico-financiera, Redistribución de recursos, Comparacción jurídica, Derechos justiciables, Justicia constitucional, Hacienda pública, Constitucionalismo de la crisis.

FECHA DE RECEPCIÓN: 23.11.2018

FECHA DE ACEPTACIÓN: 5.02.2019 